\title{
Enabling direct Preferential Crystallization in a Stable Racemic Compound System
}

\author{
Lina C. Harfouche $\uparrow$ Clément Brandel,$\uparrow^{*}$ Yohann Cartigny, $\uparrow$ Joop H. ter Horst, $\ddagger$ Gérard Coquerel, $\uparrow$ and \\ Samuel Petit ${ }^{*}$ \\ † Universite de Rouen Normandie, UFR des Sciences et Techniques, Laboratoire SMS-EA3233, Place Emile Blondel, \\ 76821, Mont-Saint-Aignan, France \\ ¥EPSRC Centre for Innovative Manufacturing in Continuous Manufacturing and Crystallisation (CMAC), Strathclyde \\ Institute of Pharmacy and Biomedical Sciences (SIPBS), Technology and Innovation Centre, University of Strathclyde, \\ 99 George Street, Glasgow G1 1RD (UK)
}

\section{Supporting Information Placeholder}

\begin{abstract}
The preparative resolution by preferential crystallization (PC) of proxyphylline has been achieved despite the existence of a stable racemic compound. This is enabled through the careful selection of a solvent in which both the racemic compound and the metastable conglomerate possess a low nucleation rate. Induction time measurements in isobutyl alcohol show that a highly supersaturated solution $(\beta=2.3)$ remains clear for almost 1 hour at $20 \mathrm{~mL}$ scale, revealing a slow nucleation rate. After the determination of isothermal sections in the relevant phase diagram at 10 and $25^{\circ} \mathrm{C}$, both isothermal and polythermic modes of PC could be successfully implemented. Alongside the reported case of diprophylline, this study opens opportunities to broaden the application of PC towards slowly crystallizing racemic compound.
\end{abstract}

\section{INTRODUCTION}

In the field of pharmaceutical industry, around $56 \%$ of the marketed drugs are chiral compounds, 1 of which $c a .80 \%$ are formulated as racemic mixtures, i.e. equimolar mixtures of both enantiomers.2 Although two enantiomers have the same physico-chemical properties, their biological activities (including toxicity) can be different.3 Nowadays, the biological activity of each antipode has to be established and, if different, any new chiral active pharmaceutical ingredient has to be developed from the most active enantiomer.4 The two main strategies to obtain pure enantiomer are: (i) the direct manufacturing of a single enantiomer by means of asymmetric synthesis5 and (ii) the separation of the enantiomers from their racemic mixture, sometimes combined with the racemization of the undesired enantiomer (i.e. the distomer). 6

Starting from a racemic mixture, various methods of enantiomeric separation can be envisaged, including chiral chromatography7 and enzymatic resolution.8 However, crystallization techniques remain the preferred route at the industrial scale for their high selectivity and low cost. Besides Pasteurian Resolution and Deracemization,6 Preferential Crystallization9 (PC hereafter) is an attractive process with high selectivity and efficiency. Indeed, successive crystallization of the two enantiomers -supposed here nonracemizable during the crystallization- allows them to be separated quantitatively. Such PC processes actually consist of out-of-equilibrium stereoselective crystallizations with a high degree of chiral discrimination, triggered by seeding a racemic or slightly enriched supersaturated solution with single enantiomer seed crystals.10 The implementation of PC is simplified by the knowledge of the heterogeneous equilibria between both enantiomers in the solid state since it is commonly thought that PC is only applicable when the racemic mixture crystallizes as a conglomerate, i.e. a physical mixture of enantiopure crystals. For chiral compounds giving rise to a stable racemic compound (i.e., a 1:1 defined compound between both enantiomers) or solid solution (i.e., a single solid phase which does not discriminate between enantiomers), PC is assumed to be non-applicable. This strongly limits the scope of PC as only roughly $5 \%$ of racemic mixtures crystallize as conglomerates whereas the vast majority of around 95\% exist as racemic compounds. Therefore, the strategy for the implementation of PC in case of racemic compound forming systems is usually to convert the racemic compound into a diastereomer solid or a conglomerate by using a crystallization partner in order to form a salt,11 a solvate 12 or a cocrystal.13 The scope of PC would obviously be widened if this resolution method could be implemented for chiral compounds forming stable racemic compounds.

In 2013, we reported that the chiral compound Diprophylline (Scheme 1a, DPL hereafter)14 exhibits a rich solid state landscape with no less than four crystal forms, including a stable racemic compound, two metastable solid solutions and a metastable conglomerate. In the course of this study, we found that a solution of racemic DPL in polar solvents such as water, DMSO and DMF can remain highly supersaturated for several hours before any spontaneous nucleation. This large metastable zone width (MSZW hereafter), in which the nucleation of the stable form (and any other form) is hindered, served the successful implementation of PC, leading to a pure enantiomer product by using this unconventional process.

Beside the careful analysis of chiral discrimination mechanism 15 it can be presumed that the key parameter for the 
successful implementation of PC despite the absence of a stable conglomerate is the use of a solvent in which spontaneous nucleation is strongly delayed, giving rise to a large MSZW, even at high supersaturation. This feature allows the use of metastable equilibria associated to the conglomerate whereas the stable equilibria of the racemic compound can be overpassed. Since the solubility of the conglomerate in such situation is necessarily larger than that of the racemic compound, the concentration should be high enough to reach a value at which there exists a sufficient supersaturation with respect to the conglomerate.

Assuming that a solvent fulfilling the above criteria can be identified, the applicability of PC might be envisaged for any chiral compound crystallizing as a stable racemic compound, which would considerably expand the scope of chiral resolution by PC. The associated strategy should therefore involve a screening procedure aiming at identifying a solvent in which a large MSZW can be reached at the working temperature, via the measurement of induction times.16

Scheme 1. Chemical structure of (a): (RS)-DPL and (b): (RS)-PXL. The chiral center is denoted with a star.<smiles>Cn1c(=O)c2c(ncn2C[C@@H](O)CO)n(C)c1=O</smiles><smiles>C[C@H](O)Cn1cnc2c1c(=O)n(C)c(=O)n2C</smiles>

The present paper reports on the application of direct PC of the racemic compound proxyphylline. The selected compound is proxyphylline (PXL hereafter, Scheme $1 \mathrm{~b}$ ) a xanthine-type bronchodilator drug from the series of theophylline derivatives that acts as a cardiac stimulant, vasodilator and bronchodilator 17 closely related to DPL. This work gives a proof-of-concept for PC of a stable racemic compound and describes a basic process design procedure including a solvent selection procedure for PXL as well as an approach to identify optimal PC process conditions in the selected solvent.

\section{MATERIALS AND METHODS}

2.1. Materials. Racemic 7-(2-Hydroxypropyl) theophylline (purity >98.0\%) was purchased from TCI EUROPE (Zwijndrecht-Belgium) and used as received. HPLC grade solvents and other reagents were purchased and used as received.

2.2. Synthesis of the Pure Enantiomer of Proxyphylline. Enantiopure proxyphylline was synthesized by analogy with a published procedure 18 from theophylline and enantiopure propylene oxide. A mixture of anhydrous theophylline (5 $\mathrm{g}$, $27.75 \mathrm{mmol}$ ), (R)-propylene oxide (purity $99 \%$, ee 97\%) (5 g, $86.08 \mathrm{mmol}, 6 \mathrm{~mL}$ ) and a catalytic amount of triethylamine (1 $\mathrm{g}, 7.17 \mathrm{mmol}, 1 \mathrm{~mL})$ in methanol $(40 \mathrm{~mL})$ was stirred for $3 \mathrm{~h}$ at reflux until complete dissolution. After cooling the mixture, the solvent was evaporated under reduced pressure. Then, $20 \mathrm{~mL}$ of methanol were added, and the flask was stored in the fridge $\left(-18{ }^{\circ} \mathrm{C}\right)$ for $4 \mathrm{~h}$ until crystallization. The obtained solid was filtered off and washed with cold ethanol $(15 \mathrm{~mL})$ yielding the desired product (S)-7-(2-Hydroxypropyl) theophylline, $(S)$ PXL, as a white crystalline solid ( $4 \mathrm{~g}, 16.78 \mathrm{mmol}$, yield $=61 \%$ ) - mp 149.5 ${ }^{\circ} \mathrm{C}$ \{Ref.19 142-150 ${ }^{\circ} \mathrm{C}$ and Ref.20 150.5-151.5 ${ }^{\circ} \mathrm{C}$;
$[\alpha]_{\mathrm{D} 20}=-53^{\circ}\left(c=1.00 \mathrm{mg} / \mathrm{mL}, \mathrm{CHCl}_{3}\right)\left\{\operatorname{Ref} .18:[\alpha]_{\mathrm{D} 20}=-54^{\circ}(c\right.$ $\left.\left.=1.00 \mathrm{mg} / \mathrm{mL}, \mathrm{CHCl}_{3}\right), 98 \% e e\right\} \cdot e e \mathrm{HPLC}=(-) 99.9 \%$.

${ }_{1} \mathrm{H}$ NMR (MHz) $\delta=1.28(\mathrm{~d}, 3 \mathrm{H}), 3.42(\mathrm{~s}, 3 \mathrm{H}), 3.60(\mathrm{~s}, 3 \mathrm{H})$, 4.07-4.3 (m, 2H), 4.45-4.53 (m, 1H), $7.62(\mathrm{~s}, 1 \mathrm{H})$.

2.3. Chiral HPLC. Purity of the obtained enantiomer was determined with chiral high-performance liquid chromatography (C-HPLC) using a CHIRALPAK IC column (DAICEL group, Chiral Technologies Europe), $250 \times 4.6 \mathrm{~mm}$. The mobile phase was a heptane:ethanol mixture (7.5:2.5, v:v), and the flow rate was $1 \mathrm{~mL} / \mathrm{min}$. The used wavelength for UV detection was $273 \mathrm{~nm}$ at $20{ }^{\circ} \mathrm{C}$. Under these conditions, retention times of 15 and 18 min were obtained for $(R)$-PXL and $(S)$-PXL respectively. An offline C-HPLC analysis was used to monitor the enantiomeric excess $(e e)$ of the liquid phase as function of time during the PC.

2.4. X-Ray diffractometry (XRPD). X-ray Powder Diffraction (XRPD) analyses were performed at room temperature using a D8 Discover diffractometer (Bruker analytic X-ray Systems, Germany) with Bragg-Brentano geometry. The instrument is equipped with a copper anticathode $(40 \mathrm{kV}, 40 \mathrm{~mA}, \mathrm{~K} \alpha$ radiation $(\lambda=1.5418 \AA))$, and a lynx eye linear detector. The diffraction patterns were recorded with a scan rate of $0.04^{\circ}(2 \theta)$ in the angular range of $3-30^{\circ} 2 \theta$, with a counting time of 4 s per step.

2.5. Solubility Measurements. The solubilities of racemic PXL in 22 different solvents were measured at $20^{\circ} \mathrm{C}$ by the standard gravimetric method.21 A suspension of racemic PXL was prepared in a solvent and stirred at $700 \mathrm{rpm}$. Temperature was controlled using a thermostated double-jacket glass vessels. After equilibration for more than 2 hours, the suspension was filtered, the solid phase in equilibrium with the solution was verified by XRPD and the saturated liquid phase was weighed before and after evaporation. The solubility $s^{*}$ was calculated in weight percent $(w \%)$ by equation 1 with $m$ the mass of the the dissolved solid and $m_{s}$ the mass of the saturated solution.

$$
s^{*}=\frac{m}{m_{s}} \times 100 \quad \text { Equation } 1
$$

2.6. Induction Time Measurements. The induction time $\left(t_{i}\right)$ i.e. the time required to detect spontaneous crystallization in a supersaturated solution, was determined at different supersaturation ratios and in different solvents. For each solvent/supersaturation couple, a suitable mass of racemic PXL was dissolved in a suitable mass of solvent by heating. The solution was then introduced in 4 different $1.5 \mathrm{~mL}$ glass vials equipped with magnetic stirrers. The vials were then placed in a Crystal 16 (Technobis, The Netherlands) 16 and stirred (800 rpm) $10{ }^{\circ} \mathrm{C}$ above their saturation temperature for at least 90 min. The clear solutions were then cooled down to $20^{\circ} \mathrm{C}$ with a cooling rate of $5{ }^{\circ} \mathrm{C} / \mathrm{min}$. The moment at which the set temperature $\left(20^{\circ} \mathrm{C}\right)$ was reached is taken as time zero $\left(t_{0}\right)$. The vials were kept at $20{ }^{\circ} \mathrm{C}$ until spontaneous crystallization was detected via the decrease of light transmission through the sample. The difference between the moment when the transmissivity started to decrease and to was taken as $t$. Once the different samples crystallized, the vials were reheated above their clear point and the procedure was repeated to ensure statistical reproduction.

The solvents that gave the longest $t_{i}$ values were also tested at a larger scale of 10-20 mL. For this purpose, a suitable amount of solvent was added to a known amount of racemic PXL and the mixture was stirred for at least $1 \mathrm{~h}$ at high temperature to ensure complete dissolution. Then the solution 
was cooled down to the crystallization temperature $T_{c}$ (10 or $20{ }^{\circ} \mathrm{C}$ ) and the $t_{i}$ value was taken as the time lapse between the moment at which the solution reached $T_{c}$ and the moment at which spontaneous crystallization occurred, detected visually. Each measurement was repeated at least three times using the same solution.

2.7. Determination of ternary isotherms between $(R)$ PXL, (S)-PXL and isobutyl alcohol. In order to determine isothermal ternary phase diagrams, the solubility values were determined in isobutyl alcohol at 25 and $10^{\circ} \mathrm{C}$ using the regular gravimetric method for (i) the stable racemic compound of PXL (RC-PXL), (ii) the pure enantiomer (R)-PXL (PE-PXL), (iii) the doubly saturated solution containing $(R)$-PXL and RC-PXL, and (iv) the equimolar mixture of $(R)$ - and $(S)$-PXL (i.e., the metastable conglomerate (MC-PXL)). Concerning (iii), the enantiomeric composition of the dry extract was measured by chiral HPLC. For (iv), the solubility of the metastable conglomerate was determined by stirring an equimolar mixture of $(R)$ and (S)-PXL (prepared manually) in a small volume of isobutyl alcohol for a few minutes under a controlled constant temperature. The solid phase in equilibrium with the saturated solution was verified systematically by XRPD.

2.8. Preferential Crystallization. Preferential Crystallization (PC) experiments using (RS)-PXL were performed in isobutyl alcohol using a $50 \mathrm{~mL}$ glass tube equipped with a magnetic stirring bar. The temperature was controlled by a cryothermostat $\left(+/-1^{\circ} \mathrm{C}\right)$. Seeding was performed once the solution reached the desired $T_{\mathrm{c}}$ in order to start the preferential crystallization. Seeds used in these experiments were obtained by recrystallization from methanol. The seeds were dried and manually ground with a mortar and a pestle (Figure S2 presents a microscopy picture of the seed material). Seeding was performed by direct introduction of the solid particles in the solution. The absence of agglomerates was controlled systematically.

The enantiomeric excess in the liquor and in the solid phase during the process was monitored by offline chiral chromatography. Vacuum filtration was performed at the end of each PC and the solid phase was washed with cold heptane (at around $-10^{\circ} \mathrm{C}$ ). The purity and solid-state form of the collected crystals were determined by respectively chiral chromatography and XRPD. Several cycles of PC were performed in two modes:9,22 Seeded Isothermal Preferential Crystallization (SIPC) and Seeded Polythermic Programmed Preferential Crystallization (S3PC).

\section{RESULTS AND DISCUSSION}

3.1. Solvent Selection. The starting assumption of this work is that the key parameter for the successful implementation of PC for a stable racemic compound-forming system is the selection of a solvent in which the spontaneous nucleation of the stable crystal form as well as the metastable conglomerate are kinetically inhibited. If a highly supersaturated solution can be maintained for a sufficiently long period of time in this solvent, seeding with a single enantiomer would mainly promote its growth whereas the stable racemic compound or the counter enantiomer would not nucleate. Obviously, in the case of a racemic forming system, PC can only be envisaged if the solution is also supersaturated with reference to the metastable conglomerate.

In a preliminary step, a large collection of solvents was tested for suitable solubility. Those solvents for which the PXL solubility at $20{ }^{\circ} \mathrm{C}$ lies between 1.5 and $50 w \%$ were further investigated by determining induction time $t_{i}$ at $1 \mathrm{~mL}$ scale (see Figure S3 and Table S1 in supporting information). For samples showing large $t_{i}$ values at $1 \mathrm{~mL}$ scale, tests were made at larger scale $(10$ or $20 \mathrm{~mL}$ ), at a supersaturation ratio $1.5 \leq \beta \leq 2.5$ in respect to the stable racemic compound (Table 1). Spontaneous nucleation of RC-PXL occurred much more rapidly at larger scales and this type of dependency of the nucleation rate with crystallizer size has been discussed elsewhere.23

3.2. Design of Preferential Crystallization processes. Despite $t_{i}$ values larger than 180 and 100 minutes found in water and 1-propanol respectively, preliminary PC attempts were unsuccessful due to the primary heterogeneous crystallization and nucleation of the stable racemic compound (RC-PXL) immediately after seeding the medium with crystals of pure enantiomer (PE-PXL). This spontaneous crystallization was detected by means of X-ray powder diffraction (XRPD) of the solid phase taken for offline analysis showing the crystallization of RC-PXL and by monitoring the enantiomeric excess $(e e)$ of the liquid phase that did not change from $0 \%$. These solvents were therefore discarded. This shows that a large metastable zone width is necessary but not sufficient to ensure the success of PC under these particular circumstances. Based on the promising $t_{i}$ results, it was chosen to further investigate the reolution process in the solvent isobutyl alcohol (IBA).

Table 1. Induction time for (RC)-PXL in different solvents.

\begin{tabular}{lllll}
\hline Solvent & $\begin{array}{l}T_{\mathrm{c}} \\
\left({ }^{\circ} \mathrm{C}\right)\end{array}$ & $\begin{array}{l}S^{*} \\
(\mathrm{~W} \%)\end{array}$ & $\beta[\mathrm{c}]$ & $\begin{array}{l}t_{\mathrm{i}} \\
(\mathrm{min})\end{array}$ \\
\hline \hline Methanol & 20 & 11.7 & 1.5 & $20[\mathrm{a}]$ \\
2-butanol & 20 & 4.6 & 2.3 & $20[\mathrm{~b}]$ \\
Ethanol & 20 & 5.5 & 1.5 & $20[\mathrm{~b}]$ \\
1,4-dioxane & 20 & 6.6 & 1.5 & $15^{[\mathrm{b}]}$ \\
Tetrahydrofuran & 20 & 5.6 & 1.5 & $5[\mathrm{a}]$ \\
DMSO & 20 & 21.4 & 2 & $15^{[\mathrm{b}]}$ \\
Ethyl acetate & 20 & 1.8 & 1.7 & $2[\mathrm{a}]$ \\
Acetonitrile & 20 & 6 & 2 & $2[\mathrm{a}]$ \\
Water & 20 & 47.7 & 2.5 & $180[\mathrm{a}]$ \\
1-propanol & 20 & 3.2 & 2 & $100[\mathrm{a}]$ \\
& 20 & 2.9 & 2.3 & $60[\mathrm{a}]$ \\
Isobutyl alcohol & 10 & 2.1 & 2.3 & $60[\mathrm{a}]$ \\
\hline
\end{tabular}

[a]20 mL scale, [b] $10 \mathrm{~mL}$ scale, [c] maximum supersaturation ratio tested.

3.2.1. Solubility Measurements and Ternary Isotherms $(\boldsymbol{R})-\mathrm{PXL} /(\boldsymbol{S})-\mathrm{PXL} / \mathrm{IBA}$. Knowledge of the ternary phase diagram is needed in order to rationalize any resolution procedure by PC. PXL can exist as a pure enantiomer crystal form (PE-PXL) and, at the racemic composition, either as a stable racemic compound (RC-PXL) or as a metastable conglomerate (MC-PXL). The solubility curves of the three crystal forms in the solvent IBA are shown in Figure 1 (the corresponding solubility values are given in Table S2). 


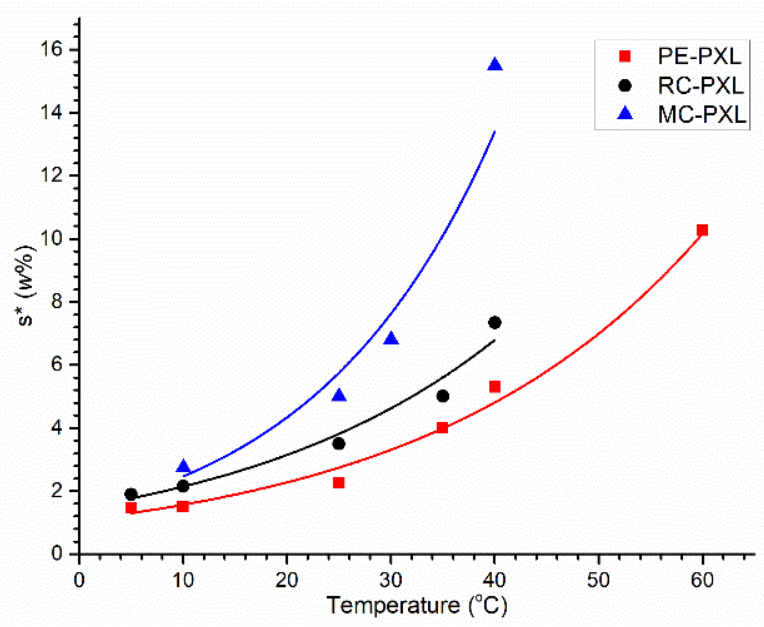

Figure 1. Solubility curves of the three crystal forms of PXL in IBA as function of temperature. PE-PXL: pure enantiomer of
PXL, RC-PXL: racemic compound, MC-PXL: metastable conglomerate. Colored lines are a guide to the eye.

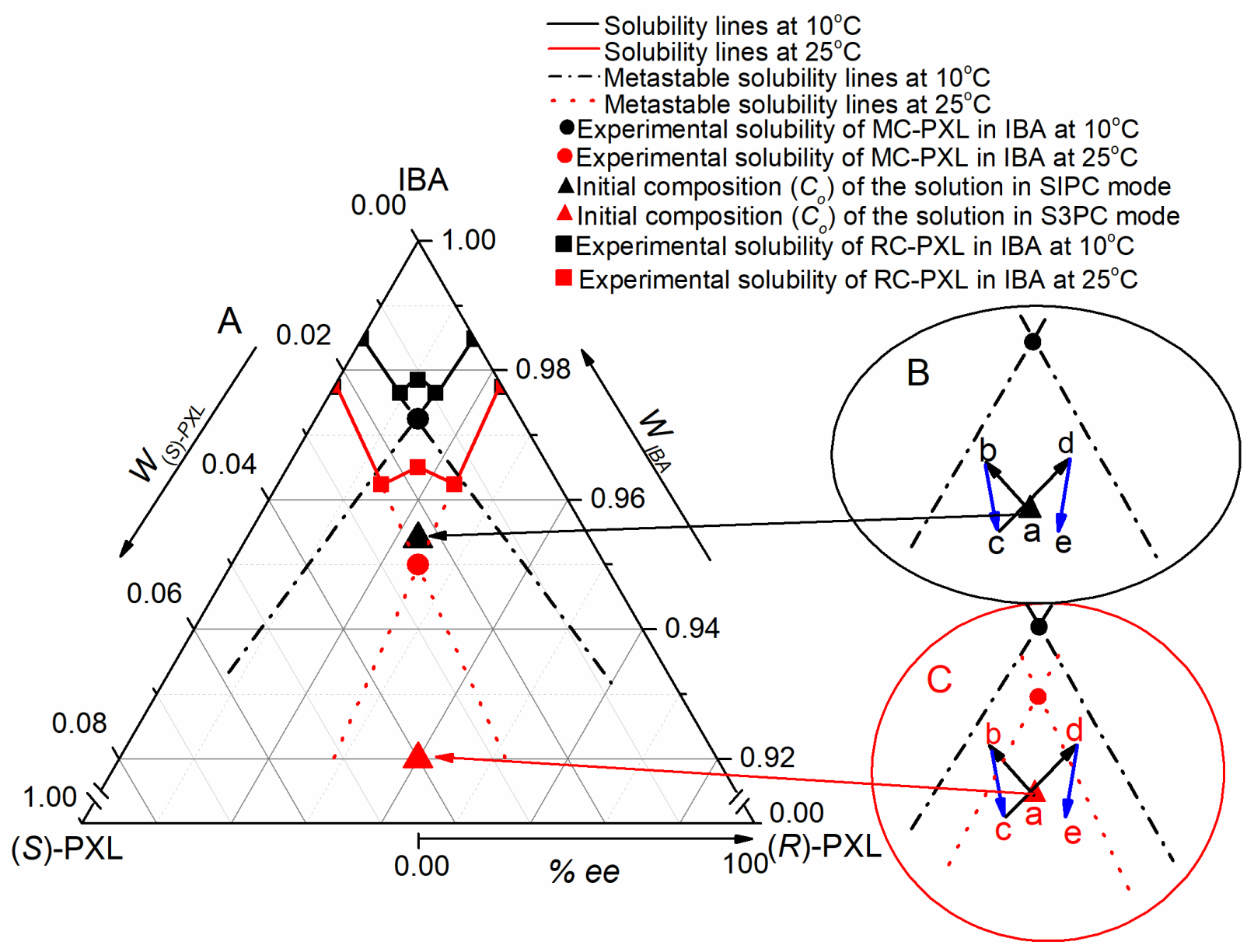

Figure 2. A: Ternary solubility phase diagram including the metastable solubility lines (dashed lines) for $(R)$ and $(S)$-PXL in IBA at 10 and $25^{\circ} \mathrm{C}$ used as $T_{c}$ for SIPC and S3PC respectively ( $W$ is for weight fraction). B: Performance of PC process for enantioseparation in SIPC mode, C: Performance of PC process in S3PC mode. Signification of (a,b,c,d and e) is described in the text.

As expected, the $s^{*}$ of the metastable conglomerate MC-PXL in IBA is higher than that of the racemic compound RC-PXL and the solubility difference substantially increases with temperature. For instance, at $10^{\circ} \mathrm{C} s^{*}$ of MC-PXL is 1.3 times higher than that of RC-PXL and roughly twice that of PE-PXL. At $40{ }^{\circ} \mathrm{C}$ the $s^{*}$ of MC-PXL becomes twice higher than that of RCPXL and trice that of PE-PXL.
These solubility data were used for the construction of the ternary isothermal sections at 10 and $25{ }^{\circ} \mathrm{C}$ (Figure 2) (temperature used for PC processes) and to plot the metastable solubility lines representing the virtual crystallization limits. The slope of the solubility curves of the enantiomers can be described using the molar solubility ratio $\alpha_{\text {mol }}$, defined as the solubility of the racemic conglomerate divided by the solubility 
of the pure enantiomer. As discussed by Jacques et al.,24 the PC process is less efficient when $\alpha_{\mathrm{mol}}$ is higher than 2 . In the present case, $\alpha$ mol ratio drops from 2.8 at $40^{\circ} \mathrm{C}$ to 1.8 at $10^{\circ} \mathrm{C}$ which indicates that PC of RC-PXL in IBA is more favorable at lower temperature.

Based on the ternary isothermal sections, two processes of PC have been used to resolve PXL in IBA: Seeded Isothermal Preferential Crystallization (SIPC) and Seeded Programmed Polythermic Preferential Crystallization (S3PC).9 In Figure 2 the initial concentration of RC-PXL in IBA $\left(C_{o}\right)$ used in this work is represented with black and red triangles respectively for SIPC and S3PC modes. Under these conditions, the solution is supersaturated at the crystallization temperature $\left(10\right.$ or $\left.20^{\circ} \mathrm{C}\right)$ regarding both RC-PXL and MC-PXL.

3.2.2. Preferential Crystallization of PXL by SIPC. As evidenced in Table 1, a supersaturated solution of racemic PXL in IBA with a supersaturation ratio of $\beta=2.3$ at $20 \mathrm{~mL}$ scale and at $10^{\circ} \mathrm{C}$ takes at least $1 \mathrm{~h}$ to crystallize spontaneously as RC-PXL which prompted us to perform a resolution procedure using the SIPC mode. Four SIPC experiments were monitored as function of time with various amount of seed mass using the conditions in table 2 . The principle of SIPC, is presented in Figure 2.B which depicts the envisaged evolution of the composition of the mother liquor during the process, it is exemplified by the SIPC experiment using $150 \mathrm{mg}$ of seeds. The starting solution saturated with RC-PXL at $T_{\mathrm{s}}=35^{\circ} \mathrm{C}\left(s^{*}=5 \mathrm{w} \%\right)$ is indicated as a black triangle in Figure 2. After rapid cooling to $T_{\mathrm{c}}=10^{\circ} \mathrm{C}\left(s^{*}=2.1 w \%, \beta=2.3\right.$ with reference to RC-PXL and 1.8 with reference to MC-PXL), the supersaturated solution is seeded with $150 \mathrm{mg}$ of fine particles of the pure $R$ enantiomer. This induces the stereoselective crystallization of this enantiomer while the enantiomeric excess of the mother liquor evolves from $e e a=0 \%$ (point a in Figure 2.B) to $e e b=5.10 \%$ (point b) within 20 minutes. At (b), the system is filtered resulting in, $212.2 \mathrm{mg}$ of crystals with an enantiomeric purity of $91.3 \%$. The liquor is then compensated with $47.73 \mathrm{mg}$ of RCPXL and with solvent, thus moving from point $\mathrm{b}$ to point $\mathrm{c}\left(e e_{c}\right.$ $=3.80 \%$ ). After homogenization of the system at $35{ }^{\circ} \mathrm{C}$, the liquor, enriched in $(S)$ enantiomer is cooled to $10^{\circ} \mathrm{C}$ and seeded with $150 \mathrm{mg}$ of $(S)$-DPL to complete the cycle and move from $3.15 \% e e c$ to $0.15 \%$ ee (point d) within 30 minutes, $201.0 \mathrm{mg}$ of solid was collected with an ee of $89.7 \%$. To move form point $\mathrm{d}$ to point e, the liquor is again compensated with $30.29 \mathrm{mg}$ of RC-PXL and solvent, homogenized at $35^{\circ} \mathrm{C}$ than cooled down to $10^{\circ} \mathrm{C}$ to start a new cycle. The process can thus be continuously cyclized.

Table 2. Starting Experimental Conditions for SIPC.

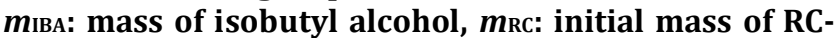
PXL dissolved in solvent, $C_{o}$ : initial total concentration of the solution, $T_{s}$ : initial saturation temperature, $T_{c}$ : constant crystallization temperature, $s_{R C_{10^{\circ} \mathrm{C}}}^{*}$ : solubility of RC-PXL at $10^{\circ} \mathrm{C}$ in IBA, $s_{M C_{10^{\circ} \mathrm{C}}}^{*}$ : solubility of MC-PXL at $10^{\circ} \mathrm{C}$ in IBA, $Y_{t h e o:}$ theoretical yield defined as $\frac{C_{o}-C_{M C_{10}} \mathrm{C}}{2 C_{0}}($ x100).

\begin{tabular}{cc} 
Conditions & SIPC \\
\hline \hline$m_{\mathrm{IBA}}(\mathrm{g})$ & 17 \\
$m_{\mathrm{RC}}(\mathrm{mg})$ & 894 \\
$C_{o}(w \%)$ & 5.0 \\
$T_{s}\left({ }^{\circ} \mathrm{C}\right)$ & 35 \\
$T_{c}\left({ }^{\circ} \mathrm{C}\right)$ & 10
\end{tabular}

\begin{tabular}{cc}
$S_{\mathrm{RC}_{10^{\circ} \mathrm{C}}}^{*}$ & 2.1 \\
$s_{\mathrm{MC}_{10^{\circ} \mathrm{C}}}^{*}$ & 2.7 \\
$Y_{\text {theo }}(\%)$ & 20 \\
\hline
\end{tabular}

In order to determine the suitable balance between seed mass and duration before filtration, the impact of the seed amount on the entrainment effect was assessed by using various amounts of seeds ranging from 50 to $150 \mathrm{mg}$. The enantiomeric excess values in the solution as a function of time are shown in Figure 3a. After seeding with $(S)$ enantiomer seed crystals, the solution is progressively enriched in the counter $(R)$ enantiomer. This is a clear indication that an out-ofequilibrium stereoselective crystallization of $(S)$-PXL is occurring in spite of the existence of the stable racemic compound.

One can also see that the higher the seed mass, the higher and the faster the liquor gets enriched in the opposite enantiomer until the seed mass reaches $100 \mathrm{mg}$. This can be either because $(S)$ enantiomer crystallize faster from solution due to larger seed crystal surface area, or because less $(R S)$ is formed when more seeds are added so that less $(R)$ is removed from solution.

In the profile given in Figure $3 a$, it is noticeable that resolution starts after seeding, e.g., with $80 \mathrm{mg}$ of $(S)$-seeds, due to secondary nucleation and growth processes, the ee of the liquid phase decreases after a certain duration due to the secondary heterogeneous nucleation of RC-PXL. From the complete monitoring curve obtained for the experiment with $80 \mathrm{mg}$ of seeds, one could expect that the filtration window of the process could be as high as 60 to 80 minutes since the enantiomeric excess of the liquor is then maximized.25 However, the optical purity in the solid phase in Figure $3 \mathrm{~b}$ indicates a gradual decrease of the crystal enantiomeric purity with process time. X-ray diffraction analyses of the crystals filtered at 15 and 30 minutes reveals that this is due to the spontaneous crystallization of the racemic compound RC-PXL after approximately 20 minutes (Figure S4) This shows that the the introduction of PE-PXL facilitates the formation of RC-PXL crystals, probably through some primary heterogeneous nucleation mechanism. Consequently, the filtration window was set at 20 or 30 minutes rather than $60-80$ min to compromise between the purity and the mass of the collected solid. 

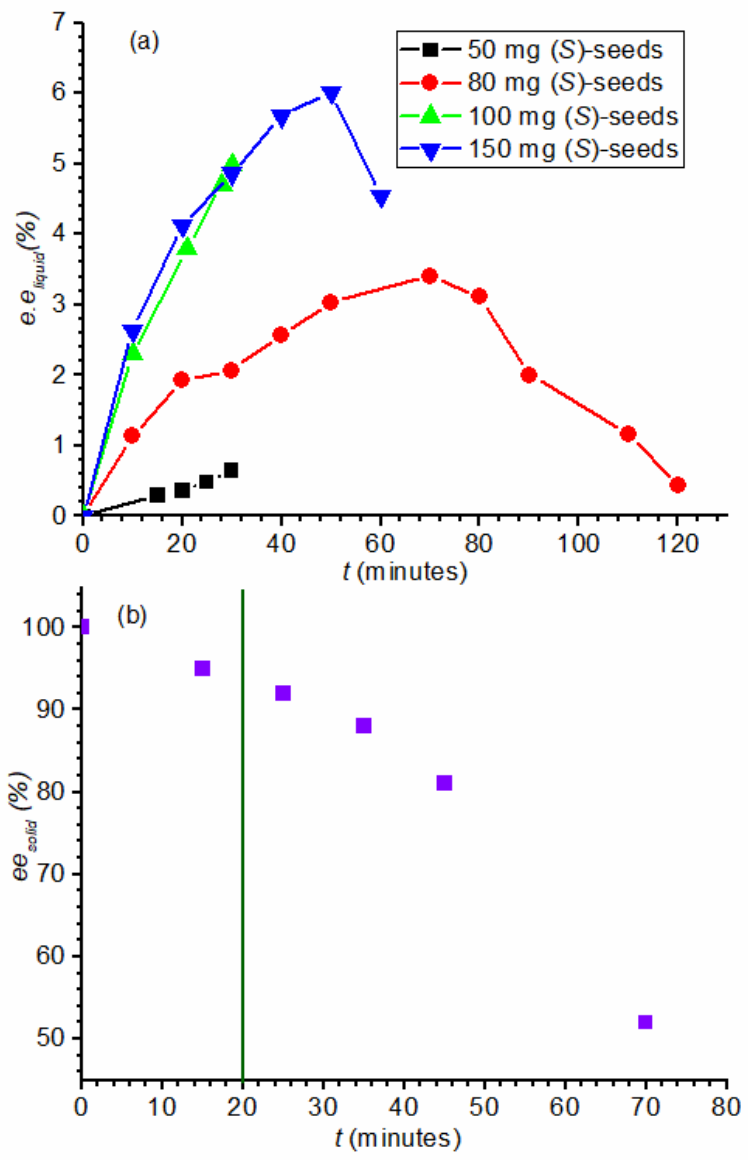

monitoring (a): the liquid phase enriched with (S)-PXL after seeding with $50 \mathrm{mg}, 80 \mathrm{mg}, 100 \mathrm{mg}$ and $150 \mathrm{mg}$ of $(S)$-PXL and (b) the solid phase with $80 \mathrm{mg}$ of $(S)$-seeds. The vertical green line crossing the point $\mathrm{t}=20$ minutes taken as filtration window shows the time required to produce $(S)$-PXL with good purity with steadily increasing the excess of $(R)$-PXL in the liquid phase.

The experimental results for 8 consecutive SIPC experiments constituting 2 SIPC cycle are given in Table 3 . These results indicate that the increase in seed mass increases the deposition rate of the pure enantiomer, which is the amount of crystalline material in units of gram/second that is deposited, due to the higher surface area offered by the larger amount of seeds and also to the slow nucleation kinetics of RC-PXL during the 20 first minutes. This significantly increases the enantiomeric excess of the liquid phase, thus accelerating the resolution process. Herein, it can be concluded that the seed mass affects the resolution rate and the yield of the produced solid in a SIPC mode. It can also be deduced from these data that the crystallization behavior of PXL during the SIPC process is mainly driven by the crystal growth of the seeds rather than secondary nucleation of PE-PXL. This assumption is supported by SEM observations made on seed crystals before and after entrainment from which it can be seen that PE-PXL has crystallized on the surface of the seeds (Figure S5). This prompted us to perform the resolution by implementing a controlled cooling profile with the aim of improving the efficiency of the process.

Figure 3. Evolution of enantiomeric excess of preferential crystallization in SIPC mode starting from racemic conditions

Table 3. Experimental results of the SIPC cycles in IBA at $10^{\circ} \mathrm{C} . e^{e} e^{(\%)}$ : initial enantiomer excess in the liquid phase, $W_{\text {seeds: }}$ mass of seeds, $t_{\text {end }}$ d duration time in minutes, $W_{c . s}$ and $O . P_{c . s}$ : weight and optical purity of the collected solid with seeds included, WP.E: weight of produced pure enantiomer, $Y_{\text {exp: }}$ experimental yield, eef (\%): enantiomeric excess of the liquid phase at the end of the process.

\begin{tabular}{ccccccccc}
\hline Run Num. & ee $(\%)$ & $W_{\text {seeds }}(\mathrm{mg})$ & tend $(\mathrm{min})$ & $W_{\text {c.s. }}(\mathrm{mg})$ & O.Pc.s. $(\%)$ & $W_{\text {P.E. }}(\mathrm{mg})$ & $Y_{\exp }(\%)$ & eef $(\%)$ \\
\hline \hline 1 & 0.00 & $(R) 50$ & 20 & 65.5 & $(R) 89.3$ & 8.49 & 4.74 & $(S) 1.30$ \\
2 & $(S) 1.00$ & $(S) 50$ & 30 & 57.6 & $(S) 90.7$ & 2.60 & 1.45 & $(R) 0.30$ \\
3 & 0.00 & $(R) 80$ & 20 & 108.0 & $(R) 92.9$ & 19.86 & 11.10 & $(S) 2.25$ \\
4 & $(S) 1.70$ & $(S) 80$ & 30 & 110.5 & $(S) 90.2$ & 18.87 & 10.55 & $(R) 0.11$ \\
5 & 0.00 & $(R) 100$ & 20 & 145.3 & $(R) 91.7$ & 32.84 & 18.36 & $(S) 4.29$ \\
6 & $(S) 3.64$ & $(S) 100$ & 30 & 140.6 & $(S) 91.6$ & 28.38 & 15.87 & $(R) 0.20$ \\
7 & 0.00 & $(R) 150$ & 20 & 212.2 & $(R) 91.3$ & 43.73 & 24.45 & $(S) 5.10$ \\
8 & $(S) 3.80$ & $(S) 150$ & 30 & 201.0 & $(S) 89.7$ & 30.29 & 16.94 & $(R) 0.15$ \\
\hline
\end{tabular}

3.2.3. Preferential Crystallization of PXL by S3PC. Compared to SIPC, the S3PC process is assumed to provide advanced control over the supersaturation profile and therefore to favor a gentler crystallization behavior, reducing the likelihood of spontaneous nucleation. Figure $2 \mathrm{C}$ ) depicts a cyclic operation of the PC process in S3PC mode to produce both enantiomers for the first two runs. A supersaturated solution was prepared at $25{ }^{\circ} \mathrm{C}\left(C_{o}=8 \mathrm{w} \%\right)$, resulting in a supersaturation ratio of $\beta=2.3$ at $25^{\circ} \mathrm{C}$ for the racemic compound RC-PXL which is identical to that applied for SIPC.
Therefore, the supersaturation with reference to MC-PXL is 1.6 slightly lower than that employed for SIPC ( $\beta$ SIPC=1.8) which creates a moderate variation of $c a .10 \%$ compared to SIPC. Starting at a lower supersaturation for MC-PXL constitutes an advantage for S3PC and thus the driving force of the crystallization is controlled by the cooling profile.

The data of four successive experiments carried out by recycling the mother liquor are reported in Table 4. Based on our SIPC results we have chosen seed masses in the range of 80-100 mg. In the first cycle and starting from a racemic composition (point (a) in Figure 2 C) the solution is seeded with 
$100 \mathrm{mg}$ PE-PXL ((R)-PXL) and linearly cooled down to $10^{\circ} \mathrm{C}$. A cooling rate of $0.75{ }^{\circ} \mathrm{C} / \mathrm{min}$ was applied. The solution moves from $0 \% e e$ (point a) to $3.3 \% e e$ (point b) and is then filtered to collect $160.0 \mathrm{mg}$ of crude crops with $92.0 \%$ of ee. After compensation with $47.0 \mathrm{mg}$ of RC-PXL and with solvent a new run can be performed (points (c), (d) and (e)) with a cooling profile of $0.375{ }^{\circ} \mathrm{C} / \mathrm{min}$. A slower cooling profile was adopted in this case because we found that at least 40 minutes of cooling are required in order to get a solution enriched with the opposite enantiomer (i.e. the required starting condition for the next run). Such a slow cooling profile systematically resulted in the concomitant spontaneous nucleation of RC-PXL. Compared to SIPC for which the nucleation of RC-PXL was sufficiently delayed at $10^{\circ} \mathrm{C}$, the higher nucleation rate of this phase in S3PC might be related to the higher concentration in solution ( $8 w \%$ for S3PC vs $5 w \%$ for SIPC as $C_{o}$ ).

This shows that the used conditions are not suited for S3PC. Additional experiments should be designed to implement this process under smoother conditions in order to assess the enantiomeric selectivity of S3PC and to reach an advanced control over the primary heterogeneous nucleation of RC-PXL.

Table 4. Four successive S3PC experiments of PXL in IBA. $e e_{o}(\%)$ : initial enantiomer excess in the liquid phase, $W_{\text {seeds: }}$ mass of seeds, tend: duration time in minutes, $W_{\text {c.s. }}$ and $O$.P $P_{\text {c.s: }}$ weight and optical purity of the collected solid with seeds included, WP.E: weight of produced pure enantiomer, Yexp: experimental yield calculated compared to the theoretical yield of $33.125 \%$, ee $(\%)$ : enantiomeric excess of the liquid phase at the end of the process.

\begin{tabular}{|c|c|c|c|c|c|c|c|c|}
\hline 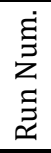 & 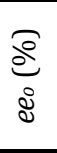 & 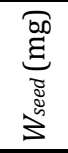 & 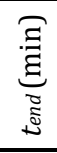 & 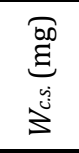 & $\begin{array}{l}\underbrace{a}_{0} \\
0 \\
0 \\
0\end{array}$ & 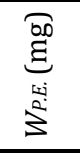 & $\underbrace{\overbrace{}^{a}}_{\substack{a \\
d}}$ & 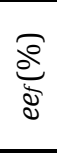 \\
\hline 1 & $\begin{array}{c}0.0 \\
0\end{array}$ & $\begin{array}{c}100 \\
(R)\end{array}$ & 20 & $\begin{array}{c}160 . \\
0\end{array}$ & $\begin{array}{c}(R) \\
92 . \\
0\end{array}$ & $\begin{array}{c}47.2 \\
0\end{array}$ & 9.96 & $\begin{array}{c}(S) \\
3.3 \\
0\end{array}$ \\
\hline 2 & $\begin{array}{c}(S) \\
2.3 \\
0\end{array}$ & $\begin{array}{c}100 \\
(S)\end{array}$ & 40 & $\begin{array}{c}210 . \\
2\end{array}$ & $\begin{array}{c}(S) \\
81 . \\
1\end{array}$ & $\begin{array}{c}70.4 \\
7\end{array}$ & $\begin{array}{c}14.9 \\
7\end{array}$ & $\begin{array}{c}(R) \\
1.5 \\
3\end{array}$ \\
\hline 3 & $\begin{array}{c}(R) \\
1.4 \\
0\end{array}$ & $\begin{array}{c}80 \\
(R)\end{array}$ & 40 & $\begin{array}{c}134 . \\
2\end{array}$ & $\begin{array}{c}(R) \\
81 . \\
2\end{array}$ & $\begin{array}{c}28.5 \\
7\end{array}$ & 6.02 & $\begin{array}{c}(S) \\
0.4 \\
0\end{array}$ \\
\hline 4 & $\begin{array}{c}(S) \\
0.2 \\
0\end{array}$ & $\begin{array}{c}100 \\
(S)\end{array}$ & 40 & $\begin{array}{c}156 . \\
0\end{array}$ & $\begin{array}{c}(S) \\
82 . \\
6\end{array}$ & $\begin{array}{c}28.8 \\
5\end{array}$ & 6.08 & $\begin{array}{c}(R) \\
1.8 \\
5\end{array}$ \\
\hline
\end{tabular}

\section{DISCUSSION}

Preferential Crystallization (PC) is assumed to be nonapplicable when a racemic mixture crystallizes as a stable racemic compound. In this work, it is demonstrated that this limitation can be overcome for proxyphylline. Even though scale-up was not performed and various experimental parameters might still be optimized, we obtained a proof of concept for implementation of PC in a system that crystallizes as a stable racemic compound. The key step of the development of PC in a metastable conglomerate system is the selection of a solvent in which the nucleation rate of the racemic compound is sufficiently low. A solvent selection method was therefore developed, mainly consisting of induction time measurements and preliminary tests of the entrainment effect. During the implementation of the PC process using both isothermal and polythermal modes, several critical factors were identified: (i) large MSZW that should exceed the ratio of solubility of conglomerate and racemic compound, and thus the absence of spontaneous nucleation of the racemic compound after seeding (ii) fast growth rate of enantiopure compound, (iii) optimal mass and quality of seeds.

\section{CONCLUSION}

We show that it is possible to widen the scope of preferential crystallization (PC) to racemic compound forming system. By inhibiting the nucleation of the stable racemic compound, it is possible to apply PC by seeding the supersaturated solution in the metastable zone with the pure enantiomer. The success of the entrainment effect depends on the nature of the solvent, the initial supersaturation, the initial enantiomeric excess in the solution and particularly on the seed amount. The large MSZW is necessary but does not appear to be the only factor enabling PC in this type of system since seeding with pure enantiomer can also trigger the primary heterogeneous nucleation of the racemic compound. Therefore, process optimization is mandatory for successful implementation of the method proposed here, and further studies are in progress to optimize process parameters such as stirring mode, supersaturation, temperature, cooling profile, mixture of solvents, and also seed quality. The present work therefore suggests new perspectives toward a possible enlargement of the application field of PC.

\section{LIST OF SYMBOLS AND ABREVIATIONS}

$\begin{array}{ll}T\left({ }^{\circ} \mathrm{C}\right) & \text { Temperature } \\ \alpha & \text { Solubility ratio } \\ \beta & \text { Supersaturation } \\ w \% & \text { Weight percent } \\ t_{i} & \text { Induction time } \\ T_{c} & \text { Crystallization temperature } \\ T_{s} & \text { Saturation temperature } \\ C_{o} & \text { Initial concentration } \\ \text { PC } & \text { Preferential crystallization } \\ \text { DMSO } & \text { Dimethyl sulfoxide } \\ \text { DMF } & \text { Dimethylformamide } \\ \text { IBA } & \text { Isobutyl alcohol } \\ \text { MSZW } & \text { Metastable zone width } \\ e e & \text { Enantiomeric excess } \\ \text { RC } & \text { Racemic compound } \\ \text { PE } & \text { Pure enantiomer } \\ \text { MC } & \text { Metastable conglomerate } \\ \text { DPL } & \text { Diprophylline } \\ \text { PXL } & \text { Proxyphylline } \\ & \end{array}$


SIPC

Seeded isothermal preferential crystallization

S3PC

Seeded polythermic preferential crystallization

\section{ASSOCIATED CONTENT}

\section{Supporting Information}

The Supporting Information is available free of charge on the ACS Publications website.

1H NMR spectrum, Solubility and induction time $\left(\mathrm{t}_{\mathrm{i}}\right)$ values in large scale, ti values in $1 \mathrm{~mL}$ scale, solubility of proxyphylline in isobutyl alcohol, SEM pictures, X-ray diffraction patterns (PDF)

\section{AUTHOR INFORMATION}

\section{Corresponding Author*}

*E-mail: samuel.petit@univ-rouen.fr

*E-mail: clement.brandel@univ-rouen.fr

\section{Author Contributions}

$\dagger \ddagger$ These authors contributed equally.

\section{Notes}

The authors declare no competing financial interests.

\section{ACKNOWLEDGMENT}

This research received funding as part of the CORE ITN Project by the European Unions Horizon 2020 Research and Innovation Program under the Marie Skłodowska-Curie Grant Agreement No. 722456 CORE ITN. Lina C. Harfouche gratefully acknowledges the hospitality that she enjoyed as a Visiting Researcher at the CMAC Laboratory of the University of Strathclyde.

\section{REFERENCES}

(1) Sanganyado, E.; Lu, Z.; Fu, Q.; Schlenk, D.; Gan, J. Chiral Pharmaceuticals: A Review on Their Environmental Occurrence and Fate Processes. Water Res. 2017, 124, 527-542.

(2) Gu, C. H.; Grant, D. J. W. Physical Properties and Crystal Structures of Chiral Drugs. In Handbook of Experimental Pharmacology: Stereochemical Aspects of Drug Action and Disposition.; Springer, Berlin., 2003; Vol. 153, pp 113-139.

(3) Smith, S. W. Chiral Toxicology: It's the Same Thing Only Different. Toxicol. Sci. 2009, 110 (1), 4-30.

(4) Nguyen, L. A.; He, H.; Pham-Huy, C. Chiral Drugs: An Overview. Int. J. Biomed. Sci. 2006, 2 (2), 85-100.

(5) Farina, V.; Reeves, J. T.; Senanayake, C. H.; Song, J. J. Asymmetric Synthesis of Active Pharmaceutical Ingredients. Chem. Rev. 2006, 106 (7), 2734-2793.

(6) Sögütoglu, L. C.; Steendam, R. R. E.; Meekes, H.; Vlieg, E.; Rutjes, F. P. J. T. Viedma Ripening: A Reliable Crystallisation Method to Reach Single Chirality. Chem. Soc. Rev. 2015, 44 (19), 6723-6732.
(7) Pirkle, W. H.; Finn, J. M.; Schreiner, J. L.; Hamper, B. C. A Widely Useful Chiral Stationary Phase for the High-Performance Liquid Chromatography Separation of Enantiomers. J. Am. Chem. Soc. 1981, 103 (13), 3964-3966.

(8) Wu, S.; Lai, S.; Lin, S.; Chu, F.; Wang, K. Direct Measurement of Enantiomeric Ratios of Enzymatic Resolution by Chiral HighPerformance Liquid Chromatography. Chirality 1991, 3 (1), 67-70.

(9) Levilain, G.; Coquerel, G. Pitfalls and Rewards of Preferential Crystallization. Cryst. Eng. Comm. 2010, 12 (7), 1983-1992.

(10) Coquerel, G. Preferential Crystallization. In Sakai K., Hirayama N., Tamura R. (eds) Novel Optical Resolution Technologies. Topics in Current Chemistry; Springer, Berlin, Heidelberg, 2007; pp 151.

(11) Li, W. W.; Spix, L.; De Reus, S. C. A.; Meekes, H.; Kramer, H. J. M.; Vlieg, E.; Ter Horst, J. H. Deracemization of a Racemic Compound via Its Conglomerate-Forming Salt Using Temperature Cycling. Cryst. Growth Des. 2016, 16 (9), 5563-5570.

(12) Pálovics, E.; Faigl, F.; Fogassy, E. Separation of the Mixtures of Chiral Compounds by Crystallization. Intech 2012, 3-38.

(13) Gadade, D. D.; Pekamwar, S. S. Pharmaceutical Cocrystals: Regulatory and Strategic Aspects, Design and Development. Adv. Pharm. Bull 2016, 6 (4), 479-494.

(14) Brandel, C.; Amharar, Y.; Rollinger, J. M.; Griesser, U. J.; Cartigny, Y.; Petit, S.; Coquerel, G. Impact of Molecular Flexibility on Double Polymorphism, Solid Solutions and Chiral Discrimination during Crystallization of Diprophylline Enantiomers. Mol. Pharmaceutics 2013, 10 (10), 3850-3861.

(15) Brandel, C.; Cartigny, Y.; Coquerel, G.; ter Horst, J. H.; Petit, S. Prenucleation Self-Assembly and Chiral Discrimination Mechanisms during Solution Crystallisation of Racemic Diprophylline. Chem. Eur. J. 2016, 22 (45), 16103-16112.

(16) Brandel, C.; ter Horst, J. H. Measuring Induction Times and Crystal Nucleation Rates. Faraday Discuss. 2015, 179, 199-214.

(17) Ito, K.; Lim, S.; Caramori, G.; Cosio, B.; Chung, K. F.; Adcock, I. M.; Barnes, P. J. A Molecular Mechanism of Action of Theophylline: Induction of Histone Deacetylase Activity to Decrease Inflammatory Gene Expression. Proc. Natl. Acad. Sci. 2002, 99 (13), 8921-8926.

(18) Borowiecki, P.; Paprocki, D.; Dudzik, A.; Plenkiewicz, J. Chemoenzymatic Synthesis of Proxyphylline Enantiomers. J. Org. Chem. 2016, 81 (2), 380-395.

(19) Ruud-Christensen, M.; Skjetne, T.; Krane, J.; Aasen, A. J. Synthesis of (R)- and (S)-Proxyphylline. Acta Chem. Scand. B 1984, 38, 331-333.

(20) Selvig, K.; Ruud-Christensen, M.; Aasen, A. J. Optical Resolution, Absolute Configuration, And Activity of the Enantiomers of Proxyphylline. J. Med. Chem. 1983, 26 (10), 1514-1518.

(21) Polenske, D.; Lorenz, H.; Seidel-Morgenstern, A. Separation of Propranolol Hydrochloride Enantiomers by Preferential Crystallization: Thermodynamic Basis and Experimental Verification. Cryst. Growth Des. 2007, 7 (9), 1628-1634.

(22) Courvoisier, L.; Ndzié, E.; Petit, M.; Hedtmann, U.; Sprengard, U.; Coquerel, G. Influence of the Process on the Mechanisms and the Performances of the Preferential Crystallization: Example with ( \pm )-5(4-Bromophenyl)-5-Methylhydantoin. Chemistry letters 2001, 30 (4), 364-365.

(23) Kadam, S. S.; Kramer, H. J. M.; Ter Horst, J. H. Combination of a Single Primary Nucleation Event and Secondary Nucleation in Crystallization Processes. Cryst. Growth Des. 2011, 11 (4), 1271-1277.

(24) Jacques, J.; Collet, A.; Wilen, S. H. Enantiomers, Racemates and Resolutions; Krieger Publishing Company: Malabar, FL, 1994.

(25) Gonella, S.; Mahieux, J.; Sanselme, M.; Coquerel, G. Spotting a Conglomerate Is Just Halfway to Achieving a Preparative Resolution by Preferential Crystallization. Org. Process Res. Dev. 2012, 16 (2), 286293. 


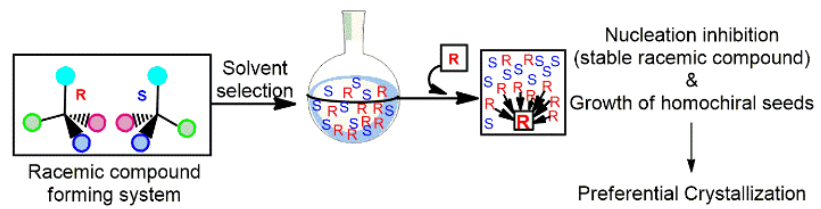

